\title{
Crown Ethers in Extraction and Sorption. I. Bromoderivatives of Benzo- and Dibenzocrown Ethers in the Sorption Processes of Elements from Acidic Water Solutions
}

\author{
Victor V. Yakshin, ${ }^{a}{ }^{1}$ Olga M. Vilkova, ${ }^{a}$ Sergei M. Pluzhnik-Gladyr, ${ }^{\mathrm{b}}$ \\ and Sergei A. Kotlyar ${ }^{\mathrm{b} 2}$ \\ a Public Company «Leading Research Institute of Chemical Technology», 115409 Moscow, Russia \\ ${ }^{\mathrm{b}}$ A. V. Bogatsky Physico-Chemical Institute, National Academy of Sciences of Ukraine, 65080 Odessa, Ukraine \\ ${ }^{\circledR}$ Corresponding authorE-mail:vyakshin@bk.ru \\ ${ }^{@ 2}$ Corresponding author_E-mail: kotlyar_sk@mail.ru
}

\begin{abstract}
For the first time the reaction ability of bromoderivatives of benzo- and dibenzocrown ethers at sorption of $\sim 30$ elements from the water solutions of nitric and muriatic acids was studied. It was found, that an introduction of one (in the case of benzocrown ethers) or two (dibenzocrown ethers) bromine atoms into the phenylene rings of macrocycle increases the sorption properties of the aimed bromides in comparison with the corresponding unsubstituted crown ethers. In this case the properties of dibenzocrown ethers differ rather strongly. So, 4',4",(5')-dibromo[3.3]dibenzo18-crown-6 has low level of activity, but in going from [4.4]dibenzo-24-crown-8 to its 4',4",(5')-dibromoderivative the sorption properties when extracting some elements from water solutions of hydrochloric acid increase in hundreds of times. Thus, a new highly selective agent for the extraction and separation of elements from multicomponent mixtures was found. Despite rather close spatial and electronic parameters, the reaction ability of 4',4",,(5')-dibromo- and 4',4',(5')-diiodo[4.4]dibenzo-24-crown-8 differs dramatically because the latter is absolutely unselective and extracts 28 elements of all studied to the same extent.
\end{abstract}

Keywords: Benzo- and dibeznocrown ethers, halogenoderivatives, sorption, acidic solutions, elements.

\section{Краун-эфиры в экстракции и сорбции. I. Бромпроизводные бензо- и Аибензокраун-эфиров в процессах сорбции элементов из кислых водных растворов}

\author{
В. В. Якшин, ${ }^{\text {a@1 }}$ О. М. Вилкова, ${ }^{a}$ C. М. Плужник-Гладырь, ${ }^{b}$ C. А. Котляр ${ }^{\text {@@2 }}$ \\ "ОАО «Ведущий научно-исследовательский институт химической технологии», 115409 Москва, Россия \\ ${ }^{\mathrm{b}}$ Физико-химический институт им. А. В. Богатского Национальной академии наук Украины, 65080 Одесса, Украина \\ ${ }^{\circledR 1}$ E-mail: vyakshin@bk.ru \\ @2E-mail: kotlyar_sk@mail.ru
}

Впервые изучена реакциинная способность бромпроизводных бензо- и дибензокраун-эфиров при сорбции >30 элементов из азотно- и солянокисльх водных растворов. Обнаружено, что введение одного (бензокраунэфиры) либо двух (дибензокраун-эфиры) атомов брома в фениленовые кольца макроцикла повыщает сорбционные свойства целевых бромидов по сравнению с соответствующими незамещенньми краунэфирами. Дибензокраун-эфиры при этом, сильно различаются по своим свойствам. Если 4',4”,(5”)-дибром [3.3]дибензо-18-краун-6 малоактивен, то при переходе от [4.4]дибензо-24-краун-8 к его 4',4",(5')-дибромпроизводному, сорбиионные свойства последнего при извлечении некоторых элементов из солянокисльх водных растворов увеличиваются в сотни раз. Таким образом, обнаружен новый высокоселективный реагент для извлечения и разделения элементов из многокомпонентных смесей. Невзирая на достаточно близкие пространственные и электронные параметры, реакционная способность 4',4",,(5')-дибром- и 4',4",,(5')-дииод[4.4]дибензо-24-краун-8 значительно различается, поскольку последний полностью неселективен, приблизительно одинаково извлекая 28 из изученных элементов.

Ключевые слова: Бензо- и дибензокраун-эфиры, галогенпроизводные, сорбция, кислые растворы, элементы. 


\section{Введение}

При извлечении и выделении поливалентных элементов из технологических и природных объектов, современные сорбционные методы часто не обеспечивают нужный результат, что обычно связано с их малой селективностью. ${ }^{[1,2]}$ Этот факт требует создания инновационных сорбционных технологий, позволяющих осуществить индивидуальное либо групповое извлечение микроэлементов с высокими коэффициентами концентрирования.

Селективность комплексообразования катионов металлов с краун-эфирами (КЭ) стала предпосылкой разработки высокоэффективных аналитических методик определения и разделения ионов металлов. ${ }^{[3-5]}$ Интерес к КЭ, закрепленным на поверхности неорганических сорбентов-носителей, понятен и обусловлен многочисленными возможностями применения таких материалов как комплексообразователей, сорбентов и катализаторов. В то же время, выявление характера взаимодействия водных ионных растворов с твердыми КЭ актуально для понимания механизмов образования супрамолекулярных поверхностных ансамблей («хозяин-гость», гидратов, Н-комплексов) в результате многоцентровой (полидентатной) фиксации сорбата.

Как комплексоны, из набора бензо- (БКЭ) и дибензокраун-эфиров (ДБКЭ) наиболее исследованы эндорецепторы типа (A-F), формирующие устойчивые соединения включения «хозяин-гость» с неорганическими кислотами и солями металлов, комплементарными по геометрическим и энергетическим параметрам. $^{[1-6]} \mathrm{B}$ соответствии с общей концепцией предорганизации макроциклов в таких процессах, прочность образующихся ассоциатов определяется, в основном, исходной геометрией (конформационными особенностями) рецептора, обеспечивающими максимально возможное связывание с субстратом («гостем»). [7] При формировании супрамолекулярных архитектур пространственная структура рецептора претерпевает существенные изменения, отвечающие стерическим и координационным требованиям субстрата. ${ }^{[4,5,7]}$ Это означает, что конформационно «гибкая» макрополость рецептора повышает устойчивость образующихся супрамолекулярных комплексов за счет снижения энергии деформации собственно полиэфирного фрагмента и прилегающих участков молекулы, что учитывается при дизайне новых эффективных и селективных комплексообразователей. ${ }^{[7]}$

С точки зрения простоты процесса, кислые водные растворыэлементовпредставляютсянаиболееудобными средами, где твердые БКЭ (типа А) растворимы в воде полностью (при сорбции в кислых водных растворах), либо частично (при экстракции в органическую фазу). Структурные особенности малорастворимых эндорецепторов типа ДБКЭ (B-F) преимущественно обусловлены двумя «жесткими» планарными ортофениленовыми фрагментами, соединенными оксиэтиленовыми спейсерами - $\mathrm{OCH}_{2} \mathrm{CH}_{2}$, ответственными за структурную «гибкость» макроцикла. Так, полиэфир [3.3]дибензо-18-краун-6 (В) и его производные образуют «семейство»конформационно «жестких»структур, мало склонных к низкоэнергетическим деформациям, что, в ряде случаев обуславливает высокую селективность таких лигандов в процессах экстракции металлов. ${ }^{[7]}$ Ранее нами обнаружено, что при извлечении последних из кислых водных сред, экстракционные свойства ДБКЭ (B-E) существенно зависят от взаимного расположения фениленовых заместителей в макрокольце. Так, изомеры положения, полиэфиры В и [2.4]дибензо-18-краун-6 (C), значительно различаются по своей реакционной способности. ${ }^{[8]}$ Если величины коэффицентов распределения металлов $\left(\mathrm{D}_{\mathrm{Me}}\right)$ всегда несколько выше у полиэфира $\mathbf{B}$, то коэффициенты разделения металлов $(\beta)$ на порядок и более, выше у экстрагента С. Таким образом, изомер с несимметричным относительно фенильных заместителей расположением атомов кислорода<smiles>c1ccc2c(c1)OCCOCCOCCOCCOCCO2</smiles>

A<smiles>OCCOCCOCCOCCOc1ccccc1Oc1ccccc1</smiles>

D<smiles>c1ccc2c(c1)OCCOCCOc1ccccc1OCCOCCO2</smiles>

B<smiles>OCCOCCOCCOCCOCCOc1ccccc1-c1ccccc1</smiles>

$\mathbf{E}$

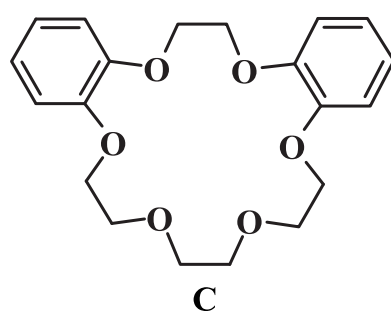<smiles>COCCOc1ccccc1OCCOCCOCCOc1ccccc1OCCOCCOCCO</smiles>

F

Рисунок 1. Гексадентатные бензо- и дибензокраун-эфиры A-F. 
значительно болееселективный экстрагент, сравнительно с широко используемым «симметричным» полиэфиром B. ${ }^{[9]}$ Однако, ДБКЭ, содержащие дифенилоксидный фрагмент (типа D) во всех случаях намного (в десятки раз) превосходят по величинам $\mathrm{D}_{\text {ме }}$ полиэфир $\mathbf{B},{ }^{[10]} \mathrm{a}$ бифенильные макроциклы (типа Е) в ряду экстракционной активности занимают промежуточное положение между D и B. ${ }^{\left[{ }^{9]}\right.}$ С увеличением числа оксиэтиленовых спейсеров в молекуле гомолога ([4.4]дибензо-24-краун-8 (F)) и его производных, гибкость макроцикла повышается, а рецептор намного легче «подстраивается» к субстрату (т.н. «наведенное соответствие»). ${ }^{[7]}$

Разработанные нами в последнее время простые и удобные способы получения хлор-, бром- и иодпроизводных БКЭ и ДБКЭ в твердой фазе, водных и органических средах ${ }^{[11-14]}$ сделали доступным все «семейство» таких галогенпроизводных (ГБКЭ). Можно обоснованно предположить, что введение атомов галогенов (брома и иода) в фениленовые кольца макроциклов должно существенно понизить растворимость целевых эндорецепторов при сорбции в кислых водных средах. Отметим, что ранее ГБКЭ в качестве сорбентов либо экстрагентов не исследовались, а роль заместителя, атома галогена, в процессах комплексообразования не обсуждалась.

В настоящем сообщении исследованы сорбционные свойства ГБКЭ типа А, В и F. Изложенные выше соображения привлекли наше внимание к 4'-бромпроизводным бензо-12-краун-4 (1), -бензо-15-краун-5 (3), -бензо-18-краун-6 (4), а также 4',4",(5'”)-дибромпроизводных [3.3]дибензо-18-краун-6 (7) и [4.4]дибензо-24краун-8 (9), (ГБКЭ 7 и 9 представляют собой смесь uис- и транс-изомеров) как объектам исследования реакционной способности (сорбционных свойств) и поиска в таком ряду новых эффективных и селективных эндорецепторов.

Нами впервые изучена реакционная способность эндорецепторов 1-10 в процессах сорбции большого числа элементов из растворов минеральных кислот (азотной и соляной) различных концентраций и сопоставлены их эффективность и селективность.

\section{Экспериментальная часть}

Сорбционные свойства твердых, порошкообразных ГБКЭ 1-10 оценивали, определяя величины коэффициентов распределения элементов ( $D$ мл/г) в процессах сорбции последних из водных солянокислых и азотнокислых (1-5 моль/дм ${ }^{3}$ р растворов. Незамещенный БКЭ 2 получали по известной методике, ${ }^{[15]}$ бромиды БКЭ 1, 3, 4 и дибромид 5 по методикам ${ }^{[11-13]}$. Незамещенные ДБКЭ 6, 8 получали, как это описано в ${ }^{[16]}$, их дибромиды 7 и 9 - по ${ }^{[1]}$, а дииодид 10 - согласно ${ }^{[14]}$. Строение и состав синтезированных макроциклов, содержавших (по данным ГЖХ) не менее 98,5\% основного вещества, подтверждены ' $\mathrm{H}$ ЯМР спектроскопией, масс-спектрометрией и элементным анализом.

Водные растворы 1, 3, 5 моль/дм ${ }^{3}$ соляной кислоты содержали по 10 мг/дм ${ }^{3}$ каждого из 32 элементов: Al, Au, B, $\mathrm{Ba}, \mathrm{Be}, \mathrm{Bi}, \mathrm{Cd}, \mathrm{Co}, \mathrm{Cr}, \mathrm{Cu}, \mathrm{Fe}, \mathrm{Ga}, \mathrm{Ge}, \mathrm{In}, \mathrm{La}, \mathrm{Li}, \mathrm{Mg}, \mathrm{Mn}, \mathrm{Mo}, \mathrm{Ni}$, $\mathrm{Pb}, \mathrm{Re}, \mathrm{Sb}, \mathrm{Sc}, \mathrm{Si}, \mathrm{Sn}, \mathrm{Sr}, \mathrm{Ti}, \mathrm{V}, \mathrm{Y}, \mathrm{Zn}, \mathrm{Zr}$; водные растворы 1, 3, 5 моль/дм ${ }^{3}$ азотной кислоты содержали по 10 мг/дм³ каждого из 27 элементов: Al, B, Ba, $\mathrm{Bi}, \mathrm{Cd}, \mathrm{Co}, \mathrm{Cr}, \mathrm{Cu}, \mathrm{Fe}, \mathrm{Ga}, \mathrm{Ge}, \mathrm{In}, \mathrm{La}$, $\mathrm{Li}, \mathrm{Mg}, \mathrm{Mn}, \mathrm{Mo}, \mathrm{Na}, \mathrm{Pb}, \mathrm{Re}, \mathrm{Sc}, \mathrm{Sr}, \mathrm{Tl}, \mathrm{V}, \mathrm{Y}, \mathrm{Zn}$.

Водные растворы соляной кислоты (концентрации 1 , 3 либо 5 моль/дм ${ }^{3}$ содержали по 10 мг/дм ${ }^{3}$ каждого из 34 элементов: Al, $\mathrm{Au}, \mathrm{B}, \mathrm{Ba}, \mathrm{Be}, \mathrm{Bi}, \mathrm{Ca}, \mathrm{Cd}, \mathrm{Co}, \mathrm{Cr}, \mathrm{Cu}, \mathrm{Fe}, \mathrm{Ga}, \mathrm{Ge}$, In, K, La, Li, Mg, Mn, Mo, Ni, Pb, Re, Sb, Sc, Si, Sn, Sr, Ti, V, Y, $\mathrm{Zn}, \mathrm{Zr}$, водные растворы азотной кислоты (концентрации 1,3 , 5 моль/дм³ ) содержали по 10 мг/дм³ каждого из 29 элементов: $\mathrm{Al}, \mathrm{B}, \mathrm{Ba}, \mathrm{Bi}, \mathrm{Ca}, \mathrm{Cd}, \mathrm{Co}, \mathrm{Cr}, \mathrm{Cu}, \mathrm{Fe}, \mathrm{Ga}, \mathrm{Ge}, \mathrm{In}, \mathrm{K}, \mathrm{La}, \mathrm{Li}, \mathrm{Mg}$, $\mathrm{Mn}, \mathrm{Mo}, \mathrm{Na}, \mathrm{Ni}, \mathrm{Pb}, \mathrm{Re}, \mathrm{Sc}, \mathrm{Sr}, \mathrm{V}, \mathrm{Y}, \mathrm{Zn}$.

Эксперимент проводили путем контактирования 0,50 г тщательно измельченного полиэфира 1-10 с 5 мл раствора указанных элементов в минеральных кислотах, при периодическом перемешивании и температуре $21 \pm 1{ }^{\circ} \mathrm{C}$. Предварительно было установлено, что равновесие процесса достигается за 24-48 ч контакта сорбента с кислым водным раствором, в связи с чем, эксперимент проводили в течение 48 ч. Аналогично, при любой степени измельчения макроциклических сорбентов (шаровая мельница и т.п.), равновесие наступало за один и тот же (менее 48 ч) период времени, поэтому размеры частиц исследованных КЭ роли не играли и нами не учитывались. По окончании процесса, сорбент отделяли фильтрацией на стеклянном фильтре Шотта, концентрацию элементов в исходных $\left(C_{\text {исх }}\right)$ и равновесных $\left(C_{\text {равн }}\right)$ растворах определяли методом атомно-эмиссионной спектрометрии с индуктивно-связанной плазмой на приборе Vista PRO (Varian) с погрешностью $\pm 5 \%$. Величину $D$ рассчитывали по уравнению:

$$
D=5\left(C_{\text {исх }}-C_{\text {равн }}\right) / 0,5 C_{\text {равн }}
$$

Полученные результаты представлены в Таблицах 1-3, причем, величины $D$ меньше 0,1 (для элементов с низкой сорбционной способностью) не приводятся.
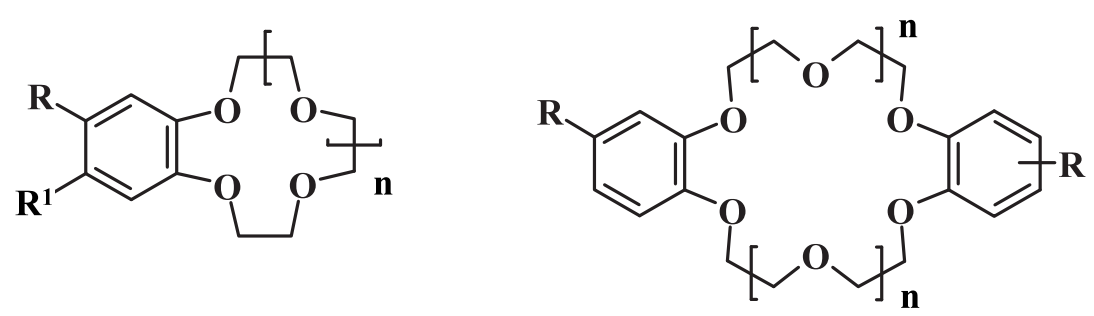

$1-5$

$6-10$

Рисунок 2. Галогенпроизводные бензо- и дибензокраун-эфиров - объекты исследования. $\mathbf{1}, \mathrm{R}=\mathrm{Br}, \mathrm{R}^{1}=\mathrm{H}, \mathrm{n}=1 ; \mathbf{2}, \mathrm{R}=\mathrm{R}^{1}=\mathrm{H}$, $\mathrm{n}=2 ; \mathbf{3}, \mathrm{R}=\mathrm{Br}, \mathrm{R}^{1}=\mathrm{H}, \mathrm{n}=2 ; \mathbf{4}, \mathrm{R}=\mathrm{R}^{1}=\mathrm{Br}, \mathrm{n}=2 ; \mathbf{5}, \mathrm{R}=\mathrm{Br}, \mathrm{R}^{1}=\mathrm{H}, \mathrm{n}=3 ; \mathbf{6}, \mathrm{R}=\mathrm{H}, \mathrm{n}=1 ; \mathbf{7}, \mathrm{R}=\mathrm{Br}, \mathrm{n}=1 ; \mathbf{8}, \mathrm{R}=\mathrm{H}, \mathrm{n}=2 ; \mathbf{9}, \mathrm{R}=\mathrm{Br}$, $\mathrm{n}=2 ; \mathbf{1 0}, \mathrm{R}=\mathrm{I}, \mathrm{n}=2$. Краун-соединения 7, 9, 10 - смесь изис- и транс-изомеров. 
V. V. Yakshin, S. A. Kotlyar et al.

Таблица 1. Коэффициенты распределения ( $D$, мл/г) элементов в процессах сорбции [4.4]дибензо-24-краун-8 (8) и его дибромпроизводным (9) из азотнокислых растворов.

\begin{tabular}{|c|c|c|c|c|c|}
\hline \multirow{3}{*}{$\begin{array}{c}\text { Элемент* } \\
\mathrm{HNO}_{3}, \text { моль/дм } \\
\end{array}$} & \multicolumn{5}{|c|}{ Сорбент - краун-эфир } \\
\hline & \multicolumn{2}{|c|}{8} & \multicolumn{3}{|c|}{9} \\
\hline & 1 & 3 & 1 & 3 & 5 \\
\hline $\mathrm{Al}$ & & & 0,15 & & \\
\hline $\mathrm{B}$ & 0,24 & 0,24 & 0,88 & 0,95 & 0,56 \\
\hline $\mathrm{Ba}$ & & 0,31 & 0,56 & 0,73 & 0,28 \\
\hline $\mathrm{Bi}$ & & 0,30 & 0,50 & 0,62 & 0,19 \\
\hline $\mathrm{Cd}$ & & 0,41 & 0,58 & 0,84 & 0,40 \\
\hline Co & & 0,25 & 0,48 & 0,62 & 0,14 \\
\hline $\mathrm{Cr}$ & 0,10 & 0,20 & 0,46 & 0,52 & \\
\hline $\mathrm{Ga}$ & & & 0,31 & 0,38 & \\
\hline $\mathrm{Ge}$ & 0,14 & & 0,36 & 0,43 & 0,32 \\
\hline In & & 0,12 & 0,30 & 0,38 & \\
\hline $\mathrm{La}$ & & & 0,17 & 0,28 & \\
\hline $\mathrm{Li}$ & & & 0,12 & 0,18 & \\
\hline $\mathrm{Mn}$ & & 0,15 & 0,32 & 0,41 & \\
\hline Mo & 0,92 & 0,97 & 1,10 & 1,20 & 0,66 \\
\hline $\mathrm{Ni}$ & & 0,25 & 0,50 & 0,68 & 0,20 \\
\hline $\mathrm{Pb}$ & 0,11 & 0,27 & 0,45 & 0,58 & 0,17 \\
\hline $\mathrm{Sc}$ & & & 0,32 & 0,42 & \\
\hline $\mathrm{Sr}$ & & & 0,16 & 0,26 & \\
\hline $\mathrm{Tl}$ & 0,32 & 1,00 & 36 & $>1000$ & $>1000$ \\
\hline $\mathrm{V}$ & & 0,11 & 0,37 & 0,41 & \\
\hline $\mathrm{Y}$ & & & 0,26 & 0,37 & \\
\hline $\mathrm{Zn}$ & & 0,15 & 0,46 & 0,62 & 0,21 \\
\hline
\end{tabular}

*Величины $D$ меньше 0,1 в таблице не приводятся.

Таблица 2. Коэффициенты распределения элементов ( $D$, мл/г) в процессах сорбции бромпроизводными бензо- и дибензокраунэфиров $1,3,4,7$ из солянокислых растворов.

\begin{tabular}{|c|c|c|c|c|c|c|c|c|}
\hline \multirow{3}{*}{$\begin{array}{c}\text { Элемент* } \\
\mathrm{HCl}, \text { моль/дм } \\
\end{array}$} & \multicolumn{8}{|c|}{ Сорбент - краун-эфир } \\
\hline & \multirow{2}{*}{$\begin{array}{l}1 \\
1\end{array}$} & \multicolumn{2}{|c|}{3} & \multirow{2}{*}{$\begin{array}{l}4 \\
3\end{array}$} & \multirow{2}{*}{$\frac{2}{1}$} & \multicolumn{3}{|c|}{7} \\
\hline & & 1 & 3 & & & 1 & 3 & 5 \\
\hline $\mathrm{Au}$ & 176 & $>1000$ & $>1000$ & 493 & $>1000$ & 0,80 & 0,46 & \\
\hline $\mathrm{Ba}$ & 1,10 & 0,28 & 0,41 & 0,25 & 0,56 & & & \\
\hline $\mathrm{Be}$ & 0,11 & 0,50 & & & & 0,19 & 0,41 & \\
\hline $\mathrm{Bi}$ & & 1,00 & 5,00 & & 1,80 & & & \\
\hline $\mathrm{Cd}$ & 0,36 & 1,10 & 6,60 & 0,55 & 0,85 & & 0,18 & \\
\hline Co & 0,22 & 0,39 & & & 0,19 & & & \\
\hline $\mathrm{Cr}$ & 0,33 & 0,14 & 0,29 & 0,20 & & & & \\
\hline $\mathrm{Cu}$ & & 0,20 & & & & & & \\
\hline $\mathrm{Fe}$ & & & 0,68 & 13,60 & & & & \\
\hline $\mathrm{Ga}$ & 46 & 0,29 & 16,7 & 478 & 0,80 & & & \\
\hline $\mathrm{Ge}$ & 0,63 & 1,30 & 2,10 & 24 & 0,68 & 0,13 & & 0,25 \\
\hline In & 0,15 & 0,12 & 0,47 & & 0,74 & & 0,29 & \\
\hline $\mathrm{La}$ & 0,17 & 0,27 & & & & & & \\
\hline $\mathrm{Mn}$ & 0,38 & 0,42 & & & 0,37 & & & \\
\hline Mo & 0,73 & & 13,70 & 6,40 & & & 0,14 & \\
\hline $\mathrm{Ni}$ & 0,28 & 0,37 & 0,41 & 0,15 & & 0,31 & 0,51 & 0,61 \\
\hline $\mathrm{Pb}$ & 0,68 & 1,30 & 1,50 & 0,86 & 2,00 & & & 0,36 \\
\hline $\mathrm{Re}$ & 0,21 & 11,80 & 12,60 & 0,85 & 1,20 & & & \\
\hline $\mathrm{Sb}$ & & 8,20 & 38,60 & 19,00 & 3,80 & 1,00 & & \\
\hline \multicolumn{9}{|l|}{$\mathrm{Sc}$} \\
\hline \multicolumn{9}{|l|}{$\mathrm{Si}$} \\
\hline Sn & 1,40 & 14,40 & 16,60 & 9,00 & 3,80 & & 0,13 & 0,18 \\
\hline $\mathrm{Ti}$ & 0,22 & 0,15 & & & & & 0,16 & \\
\hline V & 0,32 & 0,29 & 0,59 & & & & 0,21 & \\
\hline $\mathrm{Y}$ & & 0,15 & & & 0,18 & & & \\
\hline $\mathrm{Zn}$ & & 0,47 & 2,50 & & 0,87 & & & \\
\hline $\mathrm{Zr}$ & 0,33 & 2,00 & 0,15 & & 1,10 & 1,70 & 0,34 & \\
\hline
\end{tabular}

*Величины $D$ меньше 0,1 в таблице не приводятся. 
Таблица 3. Коэффициенты распределения ( $D$, мл/г) элементов в процессах сорбции [4.4]дибензо-24-краун-8 8 и его дигалогенпроизводными 9,10 из солянокислых растворов.

\begin{tabular}{|c|c|c|c|c|c|c|c|c|}
\hline \multirow{3}{*}{$\begin{array}{c}\text { Элемент* } \\
\mathrm{HCl}, \text { моль/дм } \\
\end{array}$} & \multicolumn{8}{|c|}{ Сорбент - краун-эфир } \\
\hline & \multicolumn{3}{|c|}{8} & \multicolumn{3}{|c|}{9} & \multicolumn{2}{|c|}{10} \\
\hline & 1 & 3 & 5 & 1 & 3 & 5 & 3 & 5 \\
\hline $\mathrm{Al}$ & & & & & & & & 0,33 \\
\hline $\mathrm{Au}$ & 137 & 386 & 594 & 59 & 380 & 880 & 3,60 & 2,30 \\
\hline $\mathrm{B}$ & & & & & & & 0,78 & 1,80 \\
\hline $\mathrm{Ba}$ & 0,77 & 0,56 & & & & 0,26 & 0,43 & 1,80 \\
\hline $\mathrm{Be}$ & 1,20 & 0,90 & & 0,53 & 0,36 & 0,24 & 0,76 & 1,30 \\
\hline $\mathrm{Bi}$ & & & & & & & 3,20 & 4,60 \\
\hline $\mathrm{Cd}$ & 1,00 & 1,00 & 1,70 & 0,38 & 0,49 & 1,40 & 1,90 & 2,70 \\
\hline Co & 1,00 & 0,68 & & 0,18 & & & 1,40 & 2,20 \\
\hline $\mathrm{Cr}$ & 0,44 & 0,63 & 0,79 & & & 0,28 & 1,40 & 2,30 \\
\hline $\mathrm{Cu}$ & 0,32 & 0,49 & & & & & 1,70 & 2,90 \\
\hline $\mathrm{Fe}$ & & & 41 & & & 55 & & \\
\hline $\mathrm{Ga}$ & 0,52 & 6,70 & 410 & 0,16 & 4,70 & 469 & 3,30 & 4,40 \\
\hline $\mathrm{Ge}$ & 0,71 & 0,94 & 0,19 & 0,22 & 0,50 & 0,61 & 2,80 & 4,70 \\
\hline In & 0,39 & 0,60 & 0,40 & & & 0,33 & 3,20 & 4,40 \\
\hline $\mathrm{La}$ & 0,78 & 0,53 & 0,12 & 0,14 & & 0,21 & 1,10 & 2,10 \\
\hline $\mathrm{Li}$ & & & & & & & 1,60 & 2,80 \\
\hline $\mathrm{Mn}$ & 0,75 & 0,42 & & 0,15 & & 0,22 & 1,40 & 2,40 \\
\hline Mo & & 2,70 & 8,60 & & 2,70 & 10,30 & 1,40 & 2,00 \\
\hline $\mathrm{Ni}$ & 1,40 & 1,00 & 0,26 & 0,50 & 0,36 & 0,31 & 1,50 & 2,10 \\
\hline $\mathrm{Pb}$ & 0,35 & 0,82 & 0,27 & 0,33 & & & 2,40 & 3,90 \\
\hline $\operatorname{Re}$ & 1,60 & 3,10 & 3,90 & 0,82 & 1,80 & 2,90 & 0,82 & 1,50 \\
\hline $\mathrm{Sb}$ & 2,80 & 6,50 & 44 & 1,20 & 8,10 & 70 & 1,80 & 2,80 \\
\hline $\mathrm{Sc}$ & & 0,22 & & & & & 0,73 & 1,70 \\
\hline $\mathrm{Sn}$ & 2,30 & 9,70 & 14 & 1,80 & 8,90 & 14,30 & 2,70 & 4,00 \\
\hline $\mathrm{Sr}$ & 0,34 & 0,44 & 0,44 & & & 0,25 & 0,56 & 1,30 \\
\hline $\mathrm{Ti}$ & 0,76 & 0,73 & 0,15 & & & 0,25 & 1,10 & 2,00 \\
\hline $\mathrm{V}$ & 0,94 & 0,68 & & & & & 1,40 & 2,20 \\
\hline $\mathrm{Y}$ & 0,58 & & & & & & 1,20 & 2,00 \\
\hline $\mathrm{Zn}$ & 0,17 & 0,46 & 0,28 & & & 0,32 & 1,70 & 2,50 \\
\hline $\mathrm{Zr}$ & 2,5 & 0,92 & 0,24 & & & 0,29 & 1,30 & 2,10 \\
\hline
\end{tabular}

*Величины $D$ меньше 0,1 в таблице не приводятся.

\section{Результаты и обсуждение}

Ранее нами установлено, ${ }^{[17,18]}$ что на начальных стадиях процесса эндорецептор гидратируется, а молекула воды располагается в макрополости КЭ. В присутствии сильных кислот ион гидроксония вытесняет воду с образованием устойчивого аддукта, стабилизированного водородными связями. ${ }^{[5]}$ В свою очередь, неорганические катионы, способные вытеснять ион гидроксония из макрополости, формируют комплексы типа «хозяин-гость» и переходят из водной в органическую фазу по катионобменному механизму $\left(\mathrm{M}_{\mathrm{K}}\right)$. Элементы, образующие в растворах минеральных кислот комплексные анионы $\mathrm{M}^{\mathrm{q}} \mathrm{A}_{\mathrm{q}+1}^{\ominus}$, могут входить ${ }^{[5,19,20]}$ в анионную часть комплекса эндорецептора с ионом гидроксония и сорбироваться по анионобменному механизму $\left(\mathrm{M}_{\mathrm{A}}\right)$.

При проведении сорбции из 1-5 моль/дм ${ }^{3}$ растворов $\mathrm{HNO}_{3}$ обнаружено, что макроциклы 1-3 и 5 (незамещенный БКЭ 2 служил соединением сравнения) полностью растворяются в исходных кислых растворах, в связи с чем, данные были получены только для дибромидов 4, 7 и 9. Установлено, что в указанных условиях изученные полиэфиры 4 и 7 слабо сорбируют элементы. Максимальные величины коэффициентов распределения $D$ наблюдаются для гексадентатного дибромида 7 при сорбции из растворов 3 моль/дм ${ }^{3}$ $\mathrm{HNO}_{3}$, где отмечены величины $D$, больше либо близкие 1: $\mathrm{B}(1,3)=\mathrm{Mo}(1,3)>\mathrm{Cd}(1,1)>\mathrm{Ba}(1,0)>\mathrm{Cr}(0,98)=\mathrm{Ni}(0,98)$ $=\mathrm{Zn}(0,98)$, причем, практически отсутствует селективность, поскольку одновременно извлекаются около 25 элементов с сопоставимыми значениями $D$.

Как видно из Таблицы 1, октадентатные макроциклы 8 и 9 также слабо извлекают изученные элементы из азотнокислых растворов, а сорбция имеет экстремальный характер, с максимумом при концентрации $\mathrm{HNO}_{3} 3$ моль/дм ${ }^{3}$. В оптимальных условиях ряд сорбируемости элементов полиэфиром 9 выглядит следующим образом: Мо $(D=1,2)>\mathrm{B}(0,95)>$ $\mathrm{Cd}(0,84)>\mathrm{Ba}(0,73)>\mathrm{Ni}(0,68)>\mathrm{Co}, \mathrm{Zn}(0,62)>\mathrm{Pb}(0,58)$ $>\mathrm{Cr}(0,52)>\mathrm{Ge}(0,43) \approx \mathrm{Sc}(0,42) \approx \mathrm{Mn}(0,41)>\mathrm{Ga}, \mathrm{In}(0,38)$ $\approx \mathrm{Y}(0,37)>\operatorname{La}(0,28)>\operatorname{Sr}(0,26)>\operatorname{Bi}(0,18)$.

Совершенно иная картина наблюдается в процессах сорбции элементов теми же ГБКЭ из солянокислых растворов. Установлено, что полиэфир 5 набухает уже при концентрации $\mathrm{HCl} 1$ моль/дм ${ }^{3}$, полиэфиры 1, 2, 5 растворяются в $3-5$ моль/дм ${ }^{3}$ растворах $\mathrm{HCl}$, а полиэфиры 3 и 4 - только в 5 моль/дм³ $\mathrm{HCl}$. Величины $D$ для ГБКЭ, не растворимых в солянокислых растворах в условиях эксперимента, приведены в Таблице 2, из 
Катионообменный механизм, $\mathrm{M}_{\mathrm{K}}$

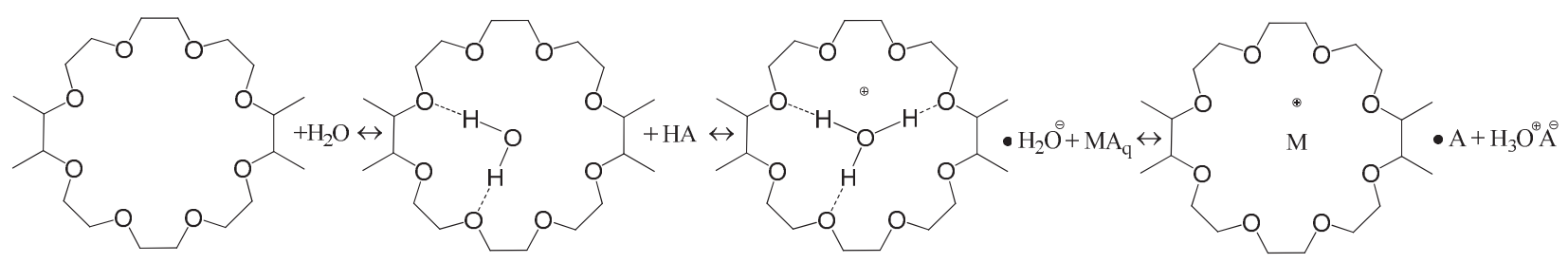

Анионообменный механизм, $\mathrm{M}_{\mathrm{A}}$

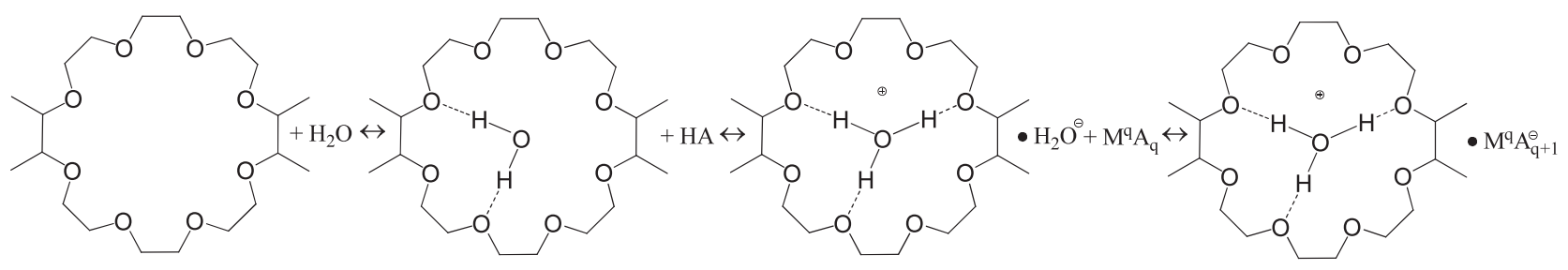

Рисунок 3. Механизм сорбции элементов краун-эфирами из кислых водных растворов, где М - элемент, А - анион, q - заряд элемента.

которой следует, что у большинства элементов (за исключением $\mathrm{Zr}$ ) величины $D$ повышаются с ростом $\left(1-5\right.$ моль/дм $\left.{ }^{3} \mathrm{HCl}\right)$ кислотности раствора. Увеличение размера макроцикла при переходе от эндорецептора 1 к 2 приводит к росту значений $D$ для $\mathrm{Au}, \mathrm{Cd}, \mathrm{Co}, \mathrm{Ge}, \mathrm{La}$, $\mathrm{Mn}, \mathrm{Ni}, \mathrm{Pb}, \mathrm{Re}, \mathrm{Sn}, \mathrm{Zr}$, в то время, как для $\mathrm{Ba}, \mathrm{Gr}, \mathrm{Ga}, \mathrm{In}$, $\mathrm{Tl}, \mathrm{V}$ значения $D$ понижаются.

Отметим изменение сорбционной способности в ряду пентадентатных макроциклов (Таблица 2). При переходе от незамещенного макроцикла 2 к бромиду 3, для $\mathrm{Bi}, \mathrm{Ga}, \mathrm{In}, \mathrm{Pb}, \mathrm{Y}, \mathrm{Zn}$ величины $D$, как этого следовало (с учетом существенного -І-эффекта атома брома $^{[21]}$ ) ожидать, понижаются. В то же время, для целого ряда элементов: $\mathrm{Au}, \mathrm{Cd}, \mathrm{Co}, \mathrm{Ge}, \mathrm{Mn}, \mathrm{Re}, \mathrm{Sb}, \mathrm{Sn}$, $\mathrm{Zr}$ наблюдается рост $D$, особенно ярко выраженный в случае $\mathrm{Re}, \mathrm{Sb}, \mathrm{Sn}$, где величина $D$ возрастает в несколько ра3, сравнительно с соединением 2. Введение второго атома брома в фениленовое кольцо БКЭ (полиэфир 4), при сорбции из 5 моль/дм ${ }^{3} \mathrm{HCl}$, снижает величины $D$ для $\mathrm{Au}, \mathrm{Ba}, \mathrm{Cd}, \mathrm{Mo}, \mathrm{Ni}, \mathrm{Pb}, \mathrm{Re}, \mathrm{Sn}$, сравнительно с соединением 3 (сорбция в 5 моль/дм ${ }^{3} \mathrm{HCl}$ ), в то время, как для $\mathrm{Fe}, \mathrm{Ga}, \mathrm{Ge}, \mathrm{Sb}$, значения $D$ остаются достаточно высокими (Таблица 2).

Интересно, что у полиэфира 7, в молекуле которого два атома брома находятся в различных фениленовых фрагментах, отмечена очень низкая реакционная способность при сорбции всех изученных элементов, независимо от кислотности водного раствора (Таблица 2).

Совершенно иная картина наблюдается при сорбции элементов дибромидом 9 из солянокислых растворов. Величины $D$ в диапазоне концентраций 1 - 5 моль/дм ${ }^{3}$ растут с увеличением кислотности, а ряд сорбируемости (Таблица 3) существенно отличается от такового для азотнокислых сред (Таблица 1) аномально высокими значениями $D$ ряда элементов: $\mathrm{Au}(D=880)>$ $\mathrm{Ga}(469)>\mathrm{Sb}(70)>\mathrm{Fe}(55)>\mathrm{Sn}(14,3)>\mathrm{Mo}(10,3)>\mathrm{Re}$ $(2,9)>\mathrm{Cd}(1,4)>\mathrm{Ge}(0,61)>\operatorname{In}(0,33) \approx \mathrm{Zn}(0,32) \approx \mathrm{Ni}(0,31)$ $>\operatorname{Zr}(0,29) \approx \mathrm{Cr}(0,28)>\operatorname{Sr}, \mathrm{Tl}(0,25)>\operatorname{Be}(0,24)>\operatorname{Mn}(0,22)$ $\approx \mathrm{La}(0,21) \approx \mathrm{Ba}(0,20)$.
Сорбционным свойствам моно- и дииодзамещенных БКЭ и ДБКЭ будет посвящена отдельная публикация, в настоящей работе дииодид $\mathbf{1 0}$ использовался лишь в качестве соединения сравнения. Установлено, что полиэфир 10 нестабилен в азотнокислых средах в течение длительного (48 ч) времени эксперимента, поэтому значения $D$ нами определены лишь в pacтворах $\mathrm{HCl}$, при концентрациях кислоты 3 и 5 моль/ дм³ ${ }^{3}$ результаты представлены в Таблице 3. Обнаружено, что, невзирая на достаточно близкие пространственные и электронные параметры ГБКЭ9 и 10, их сорбционные свойства кардинально различны. Это проявляется в полном отсутствии селективности у дииодида 10, для которого значения $D$ по 28 элементам изменяются незначительно, в пределах 1,3-4,7 (Таблица 2). Таким образом, в солянокислых растворах пространственная структура эндорецептора 10 с приблизительно равной вероятностью обеспечивает «подстройку» комплексного катиона к различным анионам металлокислот.

Особое внимание привлекает тот факт, что обычное введение заместителей, атомов брома и иода, в фениленовые фрагменты полиэфира $\mathbf{8}$, всегда увеличивает сорбционные свойства образующихся ГБКЭ 9 и 10 в процессах сорбции элементов, как из азотнокислых, так и солянокислых сред (т.е., по обоим механизмам). Наблюдаемый эффект тем более неожиданен, поскольку, как уже упоминалось выше, указанные атомы галогенов обладают заметным отрицательным индукционным эффектом, ${ }^{[21]}$ при котором, электронодонорные свойства, как минимум, четырех эфирных атомов кислорода макрополости, связанных с фениленовым кольцом, понижаются.

\section{Выводы}

Вопреки ожидаемому, введение атомов брома в фениленовые фрагменты полиэфира 8, приводит к резкому (в сотни раз) увеличению сорбционных свойств образующегося дибромида 9 при извлечении ряда элементов из солянокислых водных растворов. Макси- 
мальные коэффициенты распределения наблюдаются для $\mathrm{Au}, \mathrm{Ga}, \mathrm{Sb}, \mathrm{Fe}, \mathrm{Sn}, \mathrm{Mo}$, т.е., элементов, образующих в солянокислых растворах комплексные металлокислоты. Этот факт указывает на анионобменный механизм $\mathrm{K}_{\mathrm{A}}$ сорбции эндорецептором 9 элементов из крепких солянокислых растворов, аналогичный известным процессам экстракции этих же элементов другими КЭ. ${ }^{[5]}$

Полученные результаты обоснованно позволяют считать эндорецептор 9 новым, высокоселективным реагентом для извлечения и разделения элементов из многокомпонентных смесей. Установление всех факторов, ответственных за сорбционные свойства как эндорецепторов 1-10, так и других ГБКЭ, позволит на платформе последних выявить и использовать в новых технологиях специфичные и доступные сорбенты.

\section{References}

1. Zolotov Yu.A., Kuzmin N.M. Makrotsiklicheskiye Soedineniya $v$ Analiticheskoi Khimii (Macrocyclic Compounds in Analytical Chemistry) Nauka: Moscow, 1993. 354 p. (in Russ.).

2. Shatalov V.V., Zorina A.I., Balanovski N.V., Peganov V.A. In: Novye Podhody Khimicheskoi Tekhnologii i Praktika Primeneniya Processov Ekstartsii i Sorbtsii (Novel Approaches to Chemical Technology and Practices of Implementation of the Extraction and Sorption Processes) RAN: Sankt Peterburg, 2009, pp. 14-24 (in Russ.).

3. Khimiya Kompleksov "Gost-Khozyain», Sintez, Struktura, Primeneniye ("Host-guest» Complex Chemistry: Synthesis, Structure and Application) (F. Vogtle, E. Weber, Eds., rus. transl.) Mir: Moscow, 1988. 287 p. (in Russ.).

4. Lehn J.-M. Supramolecular Chemistry, Concepts and Perspectives Weinheim: Wiley-VCH, 1995. 281 p.
5. Yakshin V.V. Koord. Khim. 2002, 28, 142-152 (in Russ.).

6. Steed J.W., Atwood J.L. Supramolecular Chemistry, 2nd ed. New York: Wiley, 2009. 990 p.

7. Cram D.J. Angew. Chem., Int. Ed. 1986, 25, 1039-1057.

8. Yakshin V.V., Vilkova O.M., Kotlyar S.A. Dokl. Ross. Akad. Nauk. 2000, 374, 214-217 (in Russ.).

9. Yakshin V.V., Vilkova O.M., Kotlyar S.A., Grygorash R.Ya Dokl. Ross. Akad. Nauk 2001, 379, 80-82 (in Russ.).

10. Yakshin V.V., Vilkova O.M., Kotlyar S.A., Kamalov G.L. Dokl. Ross. Akad. Nauk 2007, 416, 630-632 (in Russ.).

11. Kotlyar S.A., Pluzhnik-Gladyr S.M. Macroheterocycles 2008, $1,85-89$.

12. Pluzhnik-Gladyr S.M., Rakipov I.M., Kotlyar S.A. Bashkirskii Khim. Zhurn. 2008, 15, 63-66 (in Russ.).

13. Pluzhnik-Gladyr S.M., Rakipov I.M., Kotlyar S.A. Bashkirskii Khim. Zhurn. 2008, 15, $72-75$ (in Russ.).

14. Pluzhnik-Gladyr S.M., Rakipov I.M., Kotlyar S.A. Macroheterocycles 2009, 1, 20-22.

15. Bogaschenko T., Basok S., Kulygina C., Lyapunov A., Lukyanenko N. Synthesis. 2002, 2266-2270.

16. Kotlyar S.A., Gorodnyuk V.P., Grygorash R.Ya., Chuprin G.N. Zhurn. Obsch. Khim. 1998, 68, 1189-1192 (in Russ.).

17. Laskorin B.N., Yakshin V.V. Zh. Vseros. Khim. Obsch. 1985, 30, 579-584 (in Russ.).

18. Yakshin V.V., Laskorin B.N. Dokl. Ross. Akad. Nauk 1984, 274, 868-872 (in Russ.).

19. Yakshin V.V., Tananayev I.G., Tsivadze A.Yu. In.: The Abstr. of $2^{\text {nd }}$ Intern. Symp. "Separation and Concentration in Analytical Chemistry and Radiochemistry». Krasnodar, Russia. 2005, p. 105 (in Russ.).

20. Yakshin V.V. In.: The Abstr. of the $2^{\text {nd }}$ Intern. Symp. "Separation and Concentration in Analytical Chemistry and Radiochemistry» Krasnodar, Russia, 2005, 26-30 Sept. p. 104 (in Russ.).

21. Jonson K. Uravneniye Gammeta (The Hammet Equation, rus. transl.) Mir: Moscow, 1977. 240 p. (in Russ.).

Received 16.05.2010

Accepted 22.06.2010

First published on the web 02.07.2010 